\title{
Sodium-fluoride PET-CT for the non-invasive evaluation of coronary plaques in symptomatic patients with coronary artery disease: a cross-correlation study with intravascular ultrasound
}

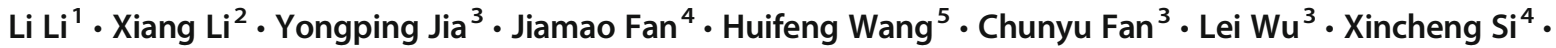 \\ Xinzhong Hao ${ }^{1}$. Ping Wu ${ }^{1}$. Min Yan ${ }^{1} \cdot$ Ruonan Wang ${ }^{1}$. Guang Hu ${ }^{1}$. Jianzhong Liu ${ }^{1} \cdot \mathrm{Zhifang} \mathrm{Wu}^{1}$. \\ Marcus Hacker ${ }^{1,2}$ (D) $\cdot$ Sijin Li ${ }^{1}$
}

Received: 22 May 2018 / Accepted: 1 August 2018 / Published online: 31 August 2018

(C) The Author(s) 2018

\begin{abstract}
Objectives The aim of this study was to evaluate the ${ }^{18} \mathrm{~F}$-sodium fluoride $\left({ }^{18} \mathrm{~F}\right.$-NaF) coronary uptake compared to coronary intravascular ultrasound (IVUS) in patients with symptomatic coronary artery disease.

Background ${ }^{18} \mathrm{~F}-\mathrm{NaF}$ PET enables the assessment of vascular osteogenesis by interaction with surface hydroxyapatite, while IVUS enables both identification and quantification of intra-plaque components.

Methods Forty-four patients with symptomatic coronary artery disease were included in this prospective controlled trial, 32 of them (30 patients with unstable angina and 2 patients with stable angina), representing the final study cohort, got additional IVUS. All patients underwent cardiac ${ }^{18} \mathrm{~F}-\mathrm{NaF}$ PET/CT and IVUS within 2 days. ${ }^{18} \mathrm{~F}-\mathrm{NaF}$ maximum tissue-to-blood ratios $\left(\mathrm{TBR}_{\max }\right)$ were calculated for 69 coronary plaques and correlated with IVUS plaque classification.

Results Significantly increased ${ }^{18} \mathrm{~F}-\mathrm{NaF}$ uptake ratios were observed in fibrocalcific lesions (meanTBR $\max _{\max }=1.42 \pm 0.28$ ), thincap atheroma with spotty calcifications ( meanTBR $_{\max }=1.32 \pm 0.23$ ), and thick-cap mixed atheroma (meanTBR $\max _{\max }=1.28 \pm$ 0.38 ), while fibrotic plaques showed no increased uptake (meanTBR $\max =0.96 \pm 0.18$ ). The ${ }^{18} \mathrm{~F}-\mathrm{NaF}$ uptake ratio was consistently higher in atherosclerotic lesions with severe calcification (meanTBR $\max _{\max }=1.34 \pm 0.22$ ). The regional ${ }^{18} \mathrm{~F}-\mathrm{NaF}$ uptake was most likely localized in the border region of intensive calcification. Coronary lesions with positive ${ }^{18} \mathrm{~F}-\mathrm{NaF}$ uptake showed some increased high-risk anatomical features on IVUS in comparison to ${ }^{18} \mathrm{~F}-\mathrm{NaF}$ negative plaques. It included a significant severe plaque burden ( $70.1 \pm 13.8$ vs. $61.0 \pm 13.8, p=0.01)$ and positive remodeling index ( $1.03 \pm 0.08$ vs. $0.99 \pm 0.07, p=0.05)$, as well as a higher percentage of necrotic tissue $(37.6 \pm 13.3$ vs. $29.3 \pm 15.7, p=0.02)$ in positive ${ }^{18} \mathrm{~F}-\mathrm{NaF}$ lesions.

Conclusions ${ }^{18} \mathrm{~F}-\mathrm{NaF}$ coronary uptake may provide a molecular insight for the characterization of coronary atherosclerotic lesions. Specific regional uptake is needed to be determined by histology.
\end{abstract}

Li Li, Xiang Li and Sijin Li shared authorship.

Electronic supplementary material The online version of this article (https://doi.org/10.1007/s00259-018-4122-0) contains supplementary material, which is available to authorized users.

Sijin Li

lisjnm123@163.com

Xiang Li

xiang.li@meduniwien.ac.at

1 Department of Nuclear Medicine, The First Hospital of Shanxi Medical University, Molecular Imaging Precision Medical Collaborative Innovation Center, Taiyuan 030001, Shanxi Province, China
2 Division of Nuclear Medicine, Department of Biomedical Imaging and Image-guided Therapy, Medical University of Vienna, Vienna, Austria

3 Department of Cardiology, The First Hospital of Shanxi Medical University, Taiyuan, Shanxi, China

4 Department of Cardiology, The Fourth People's Hospital of Linfen, Linfen, Shanxi, China

5 Department of Cardiology, Taigang General Hospital, Shanxi Medical University, Taiyuan, Shanxi, China 
Keywords Coronary plaque $\cdot{ }^{18} \mathrm{~F}$-sodium fluoride $\cdot$ Positron emission tomography $\cdot$ Intravascular ultrasound

\section{Introduction}

The progression of atherosclerosis involves complex pathophysiology, mainly including cell migration, apoptosis, inflammation, and osteogenesis, which drive calcificationprone lesions to become atherosclerotic plaques $[1,2]$.

Calcification is a remarkable biomarker of coronary atherosclerotic plaque burden, and coronary calcification on computed tomography (CT) may be a predictor of clinical disease [3]. Additional evidence has shown that the presence of intraplaque microcalcification or spotty calcification, along with thin, fibrous caps, is associated with a high risk for plaque rupture, which can lead to acute thrombosis and even fatal cardiac events [4-6].

As therapeutic strategy to prevent heart attacks, the selective reorganization of vulnerable atherosclerotic lesions has become a major task in cardiovascular research. The vulnerability of coronary plaques is conventionally assessed using the criteria of luminal stenosis, fibrous cap, lipid core, and severity of calcification by anatomical imaging, such as coronary CT angiography [7], cardiac magnetic resonance imaging (MRI) [8], and non-contrast CT [9]. Noninvasive low-dose electron-beam $\mathrm{CT}$ is a conventional imaging technique to quantify calcium in the coronary arteries, and CT-derived coronary calcium scores have been commonly used for measurement of arterial macrocalcification. However, although the extent of coronary calcification could be determined, accurate quantification of various plaque components on conventional $\mathrm{CT}$ is still challenging due to limited spatial resolution for microcalcification.

The composition of coronary plaques shows substantial variability, and it would be extremely useful to improve the differentiation of the various components within plaques. Catheter-based intravascular ultrasound (IVUS) was introduced for this purpose, and demonstrated a greater sensitivity for plaque tissue detection, which did offer insights into plaque components but in an inadequacy of characterization for intraplaque activity [10].

Currently, the early identification of patients at high-risk for plaque rupture has become a primary goal in the prevention of a cardiac event. Sodium fluoride $\left({ }^{18} \mathrm{~F}-\mathrm{NaF}\right)$ with an affinity to hydroxyapatite was introduced as a positron emission tomography (PET) tracer for the ongoing evaluation of vascular osteogenesis in atherosclerotic plaques [11, 12].

This prospective multi-modality study assessed the interrelationship between the severity of coronary calcification (CT calcium score), osteogenesis activity $\left({ }^{18} \mathrm{~F}-\mathrm{NaF}\right.$ PET uptake ratio) and the coronary plaque composition by IVUS. The major aim was to determine the feasibility the coronary ${ }^{18} \mathrm{~F}$ $\mathrm{NaF}$ PET for assessing atherosclerotic lesions of patients with cardiovascular disease, associated with intraplaque components, which could provide insight into coronary artery disease.

\section{Methods}

\section{Study participants}

At baseline clinical assessment, 44 patients with symptomatic coronary artery disease who underwent coronary angiogram for the purpose of guiding implantation of vascular scaffolds were prospectively recruited between November 2015 and August 2017. The Institutional Review Board approved this prospective controlled study and patients provided written, informed consent. Twelve patients with renal failure, vasculitis, myocarditis, and metastatic malignancy were excluded. So that finally 32 patients ( 22 men, 10 women) could be included in this prospective cross-sectional trial (Fig. 1).

\section{Imaging acquisition and analysis}

\section{Invasive coronary angiography and IVUS}

Patients $(n=44)$ with unstable and stable angina underwent conventional coronary angiography. Standard IVUS was performed at coronary artery stenosis which were guided by coronary angiography in 32 patients $[13,14]$. The catheter was positioned distal to the lesions and virtual histology data were acquired with a commercially available imaging system (Atlantis, Boston Scientific, iLabTM ultrasound imaging system) incorporating 40-MHz transducer-tip catheter (diameter $9 \mathrm{~mm}$ ) and motorized pullback at $0.5 \mathrm{~mm} / \mathrm{s}$. Quantitative IVUS measurements were performed at the same lesions and both proximal and distal reference were determined by an experienced IVUS analyst.

The cross-tissue, color-coded maps were constructed by IVUS radiofrequency signal to characterize plaque components, mainly including fibrous tissue (green), fibrolipid (yellow), lipid necrotic core (pink), and calcium (blue). The fibrous cap thickness, lipid necrotic core, plaque burden, and remodeling parameters were recorded. Coronary plaque lesions $(n=69)$ assessed by in vivo IVUS data were classified by an experienced interventional cardiologist, who was blinded to PET/CT scans, as type1, thick-cap fibroatheroma with dense necrotic tissue; type 2 , thin-cap fibroatheroma with dense necrotic tissue; Type 3 , fibrotic plaque poor necrotic tissue; and Type 4, fibrocalcific plaque with intensive calcification $[15,16]$. 
Fig. 1 The flowcharts of study. CAD: cardiovascular disease, CAG: coronary angiography, PET/CT: positron emission tomography/computed tomography, IVUS: intravascular ultrasound

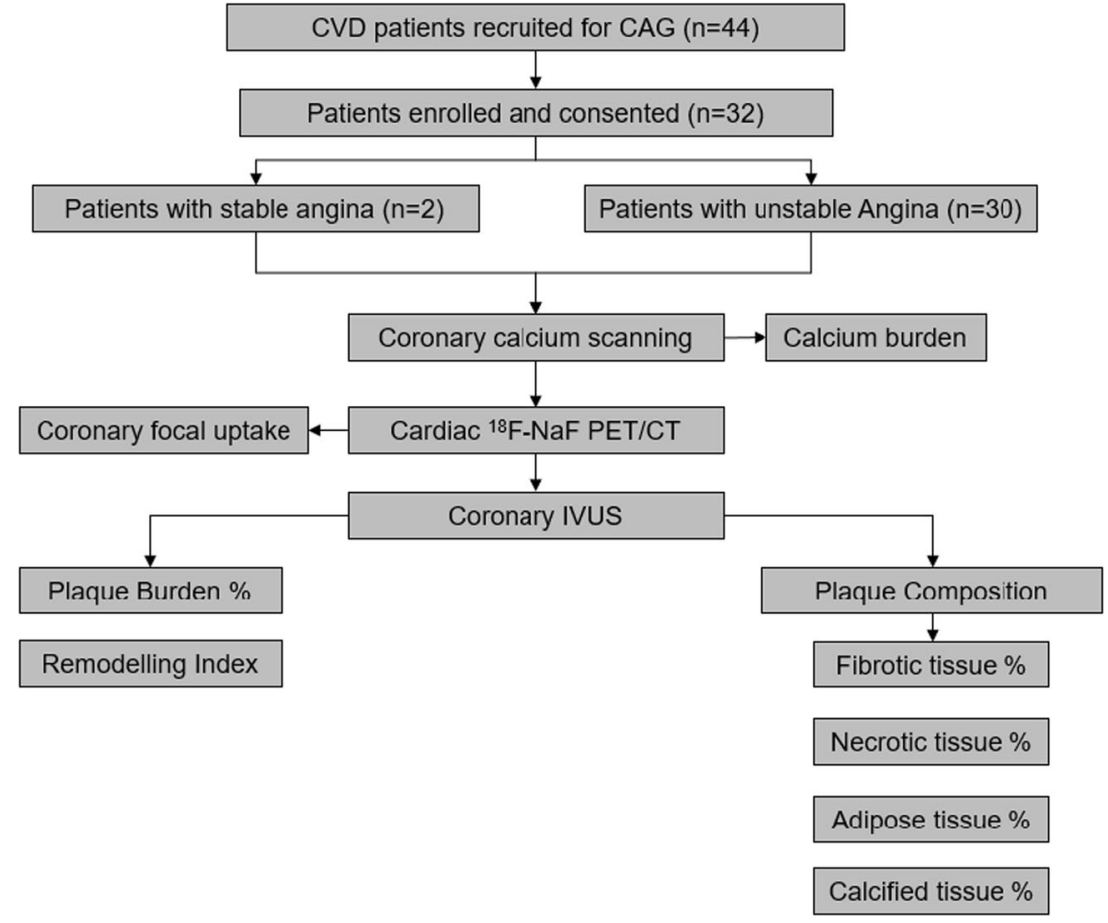

\section{${ }^{18} \mathrm{~F}-\mathrm{NaF}$ PET-CT and blood serum tests}

Electrocardiograph-gated PET-CT imaging was performed prior to IVUS in patients scheduled for percutaneous coronary intervention within 2 days. All patients underwent electrocardiography (ECG)-gated ${ }^{18} \mathrm{~F}-\mathrm{NaF}$ PET-CT imaging on a Discovery VCT combined PET-CT system (GE Healthcare, USA). Prior to the PET scan, using the combined GE Discovery VCT PET-CT scanner with an integrated 64-slice CT scanner, a low-dose CT $(120 \mathrm{kV}$, $50 \mathrm{~mA}$ ) with attenuation correction was acquired for anatomical co-registration of ${ }^{18} \mathrm{~F}-\mathrm{NaF}$ uptake. The radiochemical purity of ${ }^{18} \mathrm{~F}-\mathrm{NaF}$ reached $99 \%$, which was tested by the manufacturer (Bioscan Corporation, USA). After 60 min of tracer circulation, all patients underwent 10 -min static ${ }^{18} \mathrm{~F}-\mathrm{NaF}$ PET scanning in one bed position, covering the heart and the aortic arch.

All PET/CT scans were assessed by two experienced nuclear physicians, based on coronary anatomical imaging determined by CT scans; two-dimensional regions of interest (ROIs) with a diameter of 1-2 mm were selected manually to target the coronary vessels, including the left main coronary artery (LMCA), the left anterior descending (LAD), the left circumflex (LCx), and the right coronary artery (RCA). Maximum standardized uptake values $\left(\mathrm{SUV}_{\max }\right)$ were derived from ROIs. Maximum tissue-to-blood $\left(\mathrm{TBR}_{\max }\right)$ values were obtained by correcting SUVmax values with mean of blood pool activity ( $\mathrm{SUV}_{\text {blood }}$ ) from the three ROIs placed in the lumen of the superior vena cava $[17,18]$. Self-defined cut- off values of $\mathrm{TBR}_{\max }=1.25$ were used to categorize coronary lesions $(n=69)$ according to 1.25 times increased uptake ratio in relation to the blood pool $\left(\mathrm{TBR}_{\text {mean }}\right) .{ }^{18} \mathrm{~F}-\mathrm{NaF}$ negative atherosclerotic lesions thus had a $\mathrm{TBR}_{\max }<1.25$ and positive atherosclerotic lesions had a $\mathrm{TBR}_{\max } \geq 1.25$.

We used a standard commercial biochemical test to measure serum cholesterol, low-density lipoprotein (LDL), highdensity lipoprotein (HDL), and high-sensitivity C-reactive protein (hsCRP).

\section{Coronary calcium burden from electron beam CT}

All patients $(n=32)$ underwent calcium scanning of the four coronary arteries $(n=128)$ - the left main coronary artery (LMCA), the left anterior descending artery (LAD), the left circumflex artery ( $\mathrm{LCx})$, and the right coronary artery (RCA) - (tube voltage: $120 \mathrm{kV}$, current:200mAs) with a 3.0$\mathrm{mm}$ slice thickness and reconstructed with the B36f kernel. Volume analysis software (GE Health Care, Waukesha, WI, USA) was used to discern calcium from other tissues, with a threshold of 130 Hounsfield units. Agatston calcium scores (AS), calcium mass, and calcium volume were determined automatically. All lesions were distributed into five subgroups based on AS: group 1 (no calcification (AS $=0, n=46$ ); group 2 , minimal calcification $(0<\mathrm{AS} \leq 10, n=22)$; group 3 , mild calcification $(10<\mathrm{AS} \leq 100, n=27)$; group 4 , moderate calcification $(100<\mathrm{AS} \leq 400, n=24)$; and group 5 , severe calcification (AS>400, $n=9$ ). 


\section{Correlation of imaging methods}

For image correlation due to different image formats of the applied methods, IVUS results were used as reference for anatomical localization of coronary vessels and segments (distal, proximal or mid). PET/CT ROIs were then drawn and evaluated on the corresponding regions in the axial views.

\section{Statistics}

All continuous data were recorded as mean $\pm \mathrm{SD}$. Parametric data were statistically compared using oneway ANOVA. The Mann-Whitney U test was used for the non-parametric variables in the group comparison. The Pearson's linear correlation coefficient was used to assess the correlations between mean $\mathrm{TBR}_{\max }$ $\left(\mathrm{mTBR}_{\max }\right)$ from each patient and corresponding biochemical data including cholesterol, LDL, HDL, and hsCRP from a serum test. Multivariate linear regression analysis was also performed to determine the independent calcium factors, including coronary calcium mass and calcium volume. We used a two-way random intraobserver observation for ICCs greater than 0.9 as an indicator of excellent reproducibility between two experienced readers. All statistical analyses were performed in SPSS v. 19 (SPSS Inc., Chicago, IL). $P$-values $<0.05$ were considered statistically significant.

Intra-class correlation coefficients (ICCs) with 95\% confidence intervals were calculated to test inter- and intra-observer agreement for the TBR values. Two-way random ICC values of more than 0.8 were accepted as a measure of excellent reproducibility.

\section{Results}

\section{Patients}

Detailed clinical baseline data including cardiovascular symptoms, prior coronary intervention, cardiac events, as well as common risk factors for cardiovascular diseases, are presented in Table 1. Additional data about medication and serum biochemical measurement from a venous blood sample are also listed in Table 1.

\section{Lesion characterization of coronary plaques}

A total of 69 coronary atherosclerotic lesions were analyzed from 32 patients who underwent IVUS for tissue characterization of coronary plaques, including nonculprit thick-cap mixed atheromatous $(n=21)$, fibrotic atheromatous lesions $(n=18)$, calcified atheroma lesions $(n=8)$, and culprit thin- cap atheromatous lesions $(n=22)$ with spotty calcification. Discrepant uptake of ${ }^{18} \mathrm{~F}-\mathrm{NaF}$ in atheromatous lesions with spotty calcification, thin-cap fibrocalcified lesions with a large necrotic core and fibrotic lesions are shown in Fig. 2. Significantly increased ${ }^{18} \mathrm{~F}-\mathrm{NaF}$ signals were observed in fibrocalcific lesions $\left(\mathrm{mTBR}_{\max }=1.42 \pm 0.28\right)(n=8)$, as well as thin-cap atheroma with spotty calcifications $\left(\mathrm{mTBR}_{\max }=\right.$ $1.32 \pm 0.23)(n=22)$ and thick-cap mix atheroma $\left(\mathrm{mTBR}_{\max }=1.29 \pm 0.38\right)(n=21)$. Interestingly, ${ }^{18} \mathrm{~F}-\mathrm{NaF}$ $\mathrm{mTBR}_{\max }$ was significantly lower in fibrous plaque $\left(\mathrm{mTBR}_{\max }=0.97 \pm 0.19\right)(n=18)$ (Figs. 3 and 4). Thirtyeight lesions showed a positive ${ }^{18} \mathrm{~F}-\mathrm{NaF}$ uptake with a $\mathrm{TBR}_{\text {mean }} \geq 1.25$, while 31 lesions with a $\mathrm{TBR}_{\text {mean }}<1.25$ were rated negative by definition. Inter- and intra-observer ICCs for $\mathrm{TBR}_{\max }$ were 0.97 (95\% CI, 0.95-0.99) and 0.92 (95\% CI, $0.90-0.97)$, respectively.

The correlation between ${ }^{18} \mathrm{~F}-\mathrm{NaF}$ uptake value and anatomical features of vulnerable plaque was determined. Compared to negative ${ }^{18} \mathrm{~F}-\mathrm{NaF}$ lesions, a significant severe plaque burden $(70.1 \pm 13.8$ vs. $61.0 \pm 13.8, p=0.01)$ and remodeling ( $1.03 \pm 0.08$ vs. $0.99 \pm 0.07, p=0.05)$, as well as a higher percentage of necrotic tissue $(37.6 \pm 13.3$ vs. $29.3 \pm$ 15.7, $p=0.02$ ) were detected in positive ${ }^{18} \mathrm{~F}-\mathrm{NaF}$ lesions, but with significantly lower intraplaque fibrotic tissue (46.4 \pm 15.6 vs. $56.3 \pm 18.7, p=0.02$ ). No significantly distinguished adipose ( $12.5 \pm 4.2$ vs. $12.0 \pm 4.4, p=0.60)$ and calcified components $(3.4 \pm 2.9$ vs. $2.5 \pm 3.1, p=0.21)$ were detected between negative and positive ${ }^{18} \mathrm{~F}-\mathrm{NaF}$ lesions (Table 2).

In the sub-group assessment of defined patient populations based on Agatston calcium scores, the ${ }^{18} \mathrm{~F}-\mathrm{NaF}$ uptake ratio derived from 128 lesions was consistently higher in atherosclerotic lesions with severe calcification $\left(n=8, \mathrm{mTBR}_{\max }=\right.$ $1.38 \pm 0.19)$ compared to non-calcified coronary segments $\left(\mathrm{mTBR}_{\max }=1.16 \pm 0.31, \mathrm{AS}=0, n=46\right)$, minimal calcification $\left(\mathrm{mTBR}_{\max }=1.23 \pm 0.48,0<\mathrm{AS} \leq 10, n=22\right)$, mild calcification $\left(\mathrm{mTBR}_{\max }=1.21 \pm 0.27,10<\mathrm{AS} \leq 100, n=27\right)$, and moderate calcification $\left(\mathrm{mTBR}_{\max }=1.20 \pm 0.25,100<\right.$ $\mathrm{AS} \leq 400, n=25$ ). However, no significant inter-group difference was observed.

\section{Serum biochemistry}

${ }^{18} \mathrm{~F}-\mathrm{NaF}$ uptake ratios in relation to serum biomarkers were assessed to explore how vascular osteogenesis mechanisms are linked to underlying pathology. The hsCRP $(\mathrm{mg} / \mathrm{L})(r=0.39, p<0.05)$ showed significant correlation with ${ }^{18} \mathrm{~F}-\mathrm{NaF}$ mTBR ${ }_{\max }$ within individual patients using a multivariate linear regression. However, no statistically significant linear associations were observed between $\mathrm{mTBR}_{\max }$ and serum HDL, LDL, and cholesterol levels (Fig. 5). 
Table 1 Patient characteristics

\begin{tabular}{|c|c|c|}
\hline Characteristic & Unstable angina $(\mathrm{N}=30)$ & Stable angina $(\mathrm{N}=2)$ \\
\hline Men, $n(\%)$ & $20(67)$ & $2(100)$ \\
\hline Age, mean (SD) & $57(8)$ & $65(2)$ \\
\hline BMI $\left(\mathrm{kg} / \mathrm{m}^{2}\right)$, mean $(\mathrm{SD})$ & $25.0(3.1)$ & $26.3(0.7)$ \\
\hline HR (per min), mean (SD) & $69.2(8.7)$ & $88.0(14.1)$ \\
\hline SBP (mm Hg), mean (SD) & $137.4(16.4)$ & $137.5(6.4)$ \\
\hline DBP (mm Hg), mean (SD) & $82.8(11.2)$ & $76.5(12.0)$ \\
\hline \multicolumn{3}{|c|}{ History of cardiovascular diseases, n (\%) } \\
\hline Previous MI & $2(7)$ & 0 \\
\hline Previous CVA/TIA & $6(20)$ & 0 \\
\hline \multicolumn{3}{|l|}{ Risk factors, $n(\%)$} \\
\hline Smoking (ex or current) & $19(63)$ & $1(50)$ \\
\hline Diabetes & $10(33)$ & $2(100)$ \\
\hline Hypertension & $17(57)$ & $2(100)$ \\
\hline Hypercholesterolemia & $8(27)$ & $1(50)$ \\
\hline \multicolumn{3}{|l|}{ Medications, $n(\%)$} \\
\hline Aspirin & $13(43)$ & $1(50)$ \\
\hline Clopidogrel & $7(23)$ & 0 \\
\hline Statin & $13(43)$ & $1(50)$ \\
\hline$\beta$ blocker & $4(13)$ & $1(50)$ \\
\hline ACEI/ARB & $4(13)$ & 0 \\
\hline Calcium channel blockers & $11(37)$ & $1(50)$ \\
\hline Oral nitrates & $2(7)$ & 0 \\
\hline Other anti-hypertensive & $2(7)$ & 0 \\
\hline Insulin & $5(17)$ & $1(50)$ \\
\hline Melbine/Acarbose/Sulfonylureas & $4(13)$ & 0 \\
\hline \multicolumn{3}{|l|}{ Serum biochemistry, mean (SD) } \\
\hline Cholesterol (mmol/L) & $4.3(1.3)$ & $4.3(2.2)$ \\
\hline LDL cholesterol (mmol/L) & $2.6(1.1)$ & $3.0(2.0)$ \\
\hline HDL cholesterol (mmol/L), & $1.0(0.3)$ & $1.0(0.2)$ \\
\hline Triglycerides $(\mathrm{mmol} / \mathrm{L})$ & $2.2(2.0)$ & $0.9(0.5)$ \\
\hline Fasting blood-glucose (mmol/L) & $6.4(3.0)$ & $10.6(3.4)$ \\
\hline Hemoglobin A1c (\%) & $5.9(1.8)$ & $7.6(0.5)$ \\
\hline hemoglobin $(\mathrm{G} / \mathrm{L})$ & 141(13) & $142(13)$ \\
\hline Creatinine $(\mu \mathrm{mol} / \mathrm{L})$ & $71.4(15.5)$ & $50.9(10.1)$ \\
\hline Blood urea nitrogen $(\mu \mathrm{mol} / \mathrm{L})$ & $71.4(15.5)$ & $3.4(0.9)$ \\
\hline hsCRP (mg/L) & $4.9(1.6)$ & $7.2(0.5)$ \\
\hline \multicolumn{3}{|l|}{ Coronary calcifications } \\
\hline AJ-130 (Agatston units) & 498.1(688.8) & $387.0(449.7)$ \\
\hline Mass (mg) & 74.4(109.5) & $47.0(62.2)$ \\
\hline Volume $\left(\mathrm{mm}^{3}\right)$ & $203.8(254.7)$ & $143.5(170.4)$ \\
\hline
\end{tabular}

BMI: Body-mass index, HR: Heart rate, SBP: Systolic blood pressure, DBP: Diastolic blood pressure, MI: Myocardial infraction, CVA: Cerebrovascular accident, TIA: transient ischemic attack, ACEI: Angiotensinconverting enzyme inhibitor, ARB: Angiotensin receptor blocker, HDL: High-density lipoprotein, LDL: Lowdensity lipoprotein, CAC: Coronary artery calcium, hsCRP: high-sensitivity C-reactive protein

\section{Discussion}

Currently, there is a great demand for in vivo quantitative estimation of on-site biomarkers for atherosclerotic imaging
[19]. An abundance of evidence shows that intra-plaque activated calcification is associated with increased vulnerability of plaques and coronary events $[20] .{ }^{18} \mathrm{~F}-\mathrm{NaF}$, interacting with picomolar hydroxyapatite, a kind of calcium salt and critical 


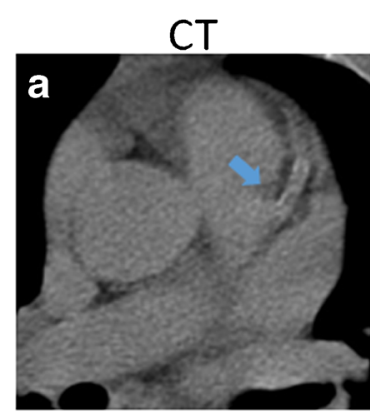

${ }^{18} \mathrm{~F}-\mathrm{NaF} \mathrm{PET} / \mathrm{CT}$
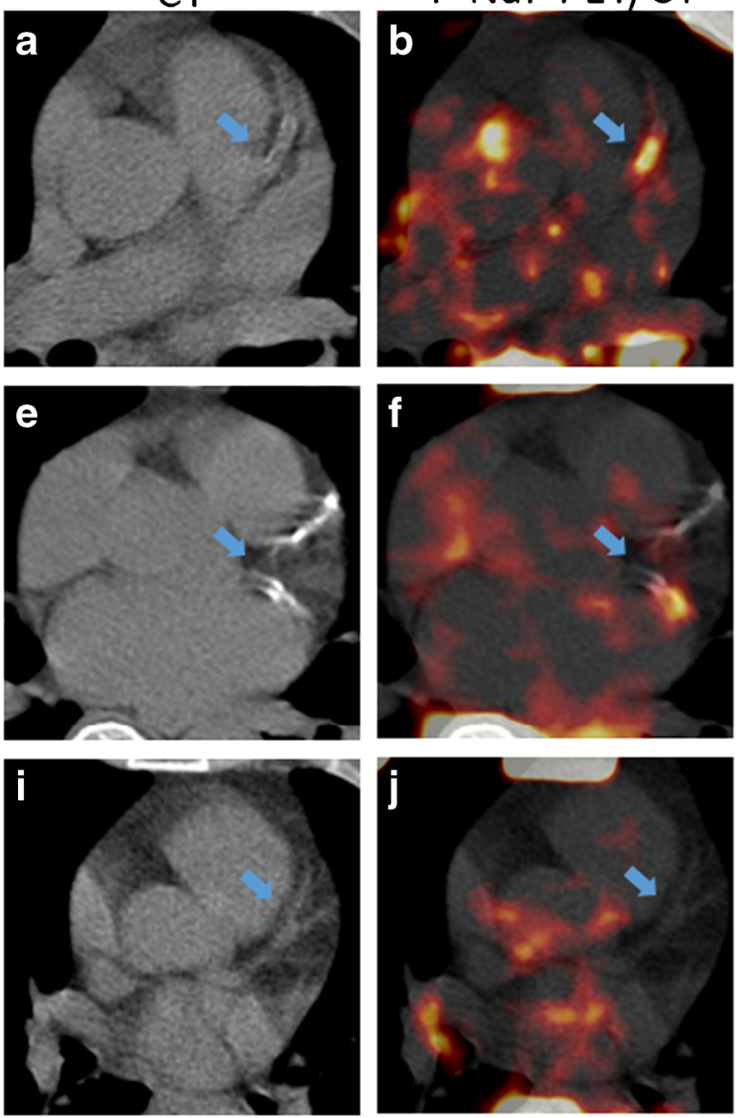

Fig. 2 Representative images of PET/CT and IVUS from three patients with unstable angina. Increased ${ }^{18} \mathrm{~F}-\mathrm{NaF}$ focal uptake was seen at atheromatous lesions with spotty calcification (a-d) in segments of the

component in the progression of vascular intimal calcification [21], enables the quantification of on-site molecular osteogenesis, which is not possible by conventional CT [22]. CT has shown great potential in the quantification of arterial calcium extent based on the Agatston calcium score [23]. Consequently, CT-derived Agatston calcium scores might overestimate the hydroxyapatite amount and there might be complementary information between ${ }^{18} \mathrm{~F}-\mathrm{NaF}$ PET and CT.

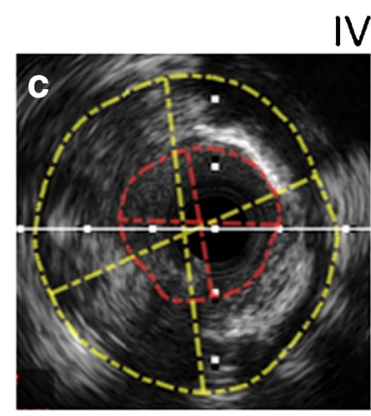

IVUS
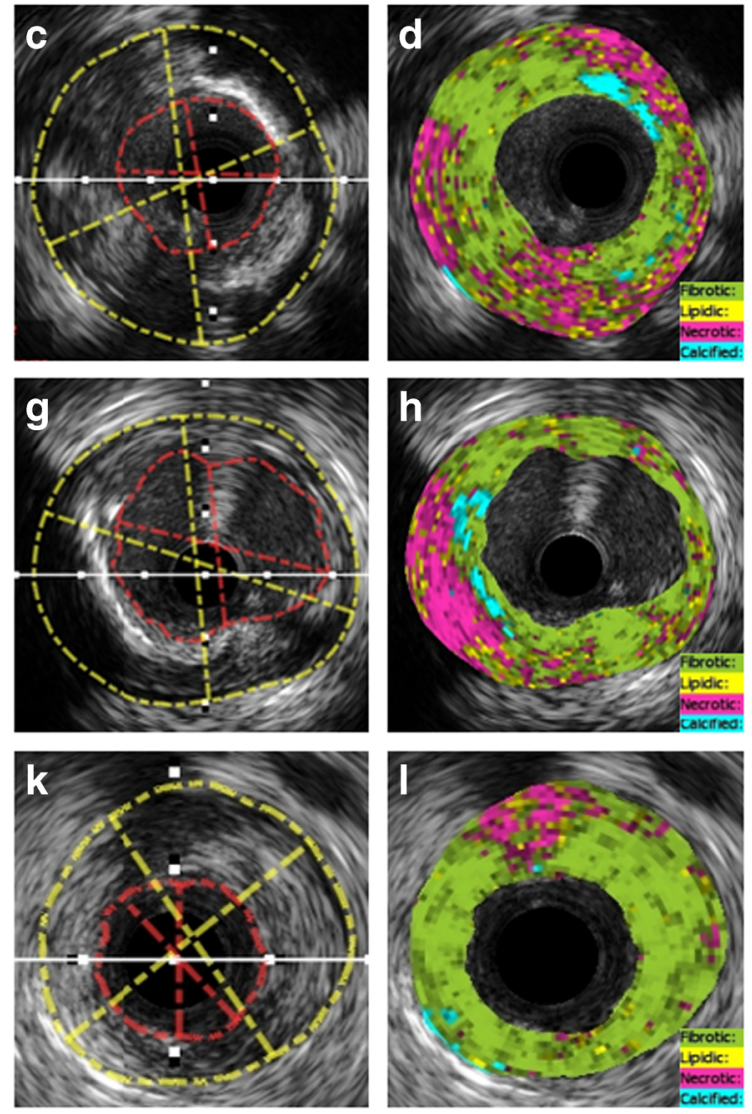

$\mathrm{LAD}$, and thin-cap fibrocalcified lesions with a large necrotic core $(\mathbf{e}-\mathbf{h})$ in segments of the LCX. But, there was no uptake in fibrotic lesions (i-l) in segments of the LAD

In the characterization of atherosclerotic lesions, prior to anatomical abnormalities observed on CT scans, ${ }^{18} \mathrm{~F}-\mathrm{NaF}$ PET has recently shown great potential to identify vascular microcalcification, which was recognized as a major component during the inflammatory process in vulnerable plaques [24]. Evidential, prospective pioneering studies showed significantly increased ${ }^{18} \mathrm{~F}-\mathrm{NaF}$ uptake ratios in patients with atherosclerosis compared to control patients. And, higher
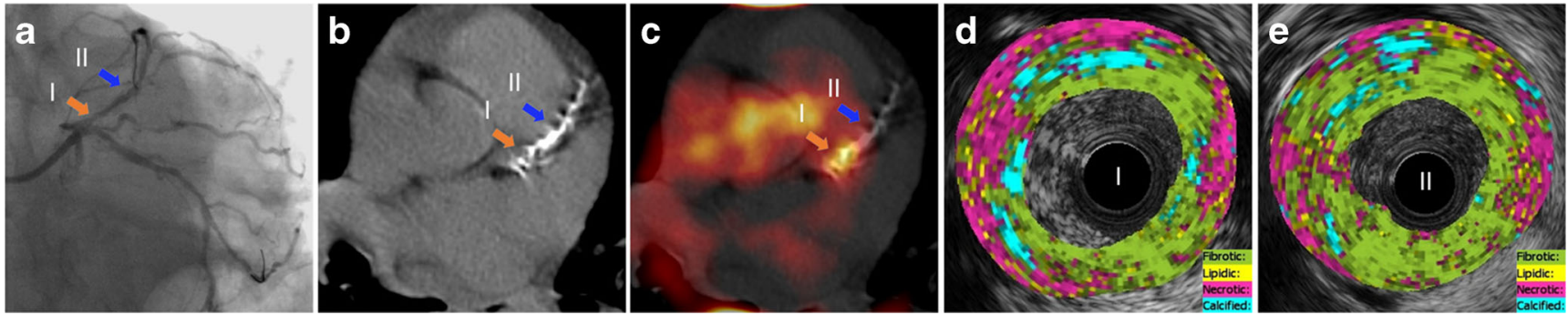

Fig. 3 Regional coronary uptake of ${ }^{18} \mathrm{~F}-\mathrm{NaF}$. A 64-year-old woman with unstable angina. (a), X-ray coronary angiogram of showed severe coronary stenosis at proximal (I) and mid (II) segments of LAD; Cardiac CT (b) and ${ }^{18} \mathrm{~F}-\mathrm{NaF}$ PET/CT (c) showed regional distribution of ${ }^{18} \mathrm{~F}-\mathrm{NaF}$ uptake within an atheromatous lesion. Representative LAD lesions showed distinct tracer accumulation along a severely fibrocalcific lesion. Prominent focal ${ }^{18} \mathrm{~F}-\mathrm{NaF}$ uptake were observed at coronary segment I verse absent focal uptake at segment II. Anatomical IVUS indicate the presence of fibroatheromatous lesion with prominently increased necrotic (35\% vs. $23 \%$ ) and calcified tissue (10\% vs. $6 \%$ ) also a slightly higher proportion of lipidic tissue ( $9 \%$ vs. $8 \%$ ), but decreased fibrotic tissue (46 vs $62 \%$ ) in segment I (d) in comparison to segment II (e) 
Fig. 4 Statistical ${ }^{18} \mathrm{~F}-\mathrm{NaF}$ uptake ratios $\left(\mathrm{mTBR}_{\max }\right)$ distribution within different types of atherosclerotic lesions $(n=69)$. Significantly increased uptake was observed at thick-cap ( $n=$ 21) and thin-cap fibroatheromas $(n=22)$ with a large necrotic core, as well as in fibrocalcified $(n=8)$ plaques compared to fibrotic plaques $(n=18)$ with less lipid necrotic tissue. $\mathrm{mTBR}_{\max }$ : mean of $\mathrm{TBR}_{\max }$ derived from all lesions in each defined group. $* p$ value $<0.05$

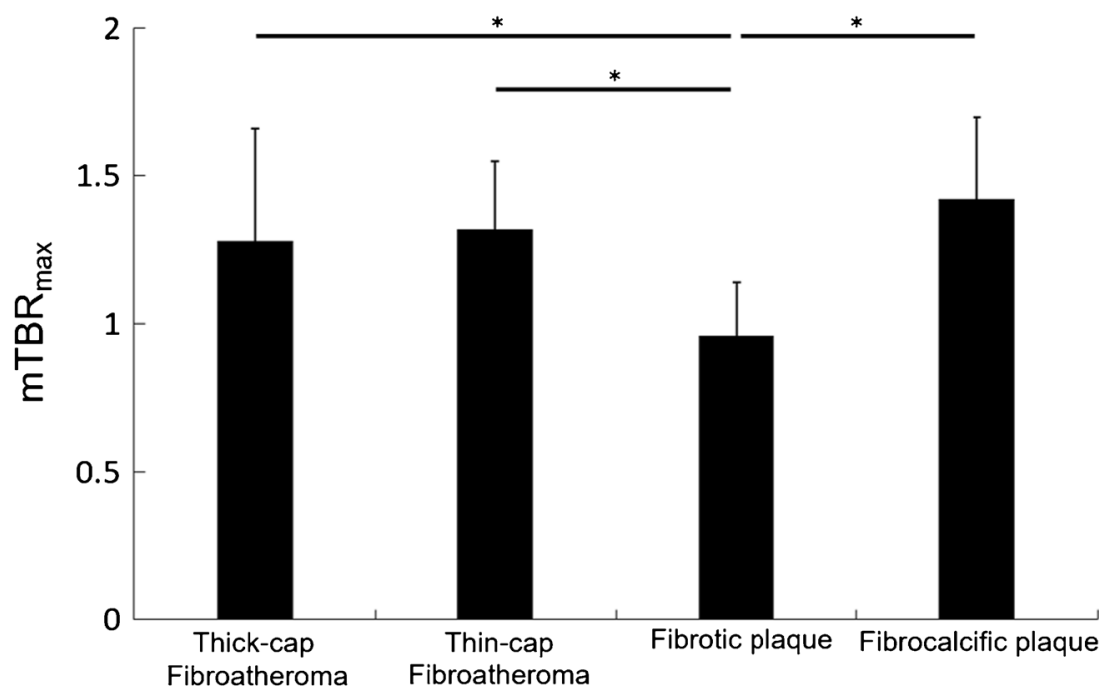

uptake value was detected in association with symptomatic, morphologically-risky coronary plaques [11]. Nevertheless, the indication of increased ${ }^{18} \mathrm{~F}-\mathrm{NaF}$ uptake within different categorized atherosclerotic lesions is still controversial.

In a previous study of ${ }^{18} \mathrm{~F}-\mathrm{NaF}$ plaque imaging, we observed that the majority of hot ${ }^{18} \mathrm{~F}-\mathrm{NaF}$ lesions were detected in mildly and severely calcified lesions on low-dose CT scans in large arteries [17], with increased ${ }^{18} \mathrm{~F}-\mathrm{NaF}$ uptake in the spotty calcifications as well as dense macrocalcifications. The results from the present coronary trial are in accordance with this previous study on large arteries. Interestingly, regional ${ }^{18} \mathrm{~F}-\mathrm{NaF}$ uptake was most likely localized in the border region of intensive calcification where there was concurrent active inflammation. Thus, the border regional ${ }^{18} \mathrm{~F}-\mathrm{NaF}$ uptake might indicate increase of calcium, and prominent intraplaque ${ }^{18} \mathrm{~F}-\mathrm{NaF}$ accumulation might predict active crystallization and accelerated progression of atherosclerosis. However, whether this active calcification drives plaque stabilization or appears due to lesion erosion needs to be determined, since osteogenic differentiation could be induced from immune cells and smooth muscle cells. A larger cohort in a prospective study has shown an inverse relationship between ${ }^{18} \mathrm{~F}-\mathrm{NaF}$

Table 2 Tissue components within negative ${ }^{18} \mathrm{~F}-\mathrm{NaF}$ lesions and positive ${ }^{18} \mathrm{~F}-\mathrm{NaF}$ lesions

\begin{tabular}{llll}
\hline Measure & $\begin{array}{l}\text { Negative } \\
\text { lesions }\end{array}$ & $\begin{array}{l}{ }^{18} \mathrm{~F}-\mathrm{NaF} \\
\text { Positive }{ }^{18} \mathrm{~F}-\mathrm{NaF}\end{array}$ & $\mathrm{p}$ value \\
\hline Remodeling index & $0.99 \pm 0.07$ & $1.03 \pm 0.08$ & 0.05 \\
Burden (\%) & $61.0 \pm 13.8$ & $70.1 \pm 13.8$ & 0.01 \\
Fibrotic tissue (\%) & $56.3 \pm 18.7$ & $46.4 \pm 15.6$ & 0.02 \\
Necrotic tissue (\%) & $29.3 \pm 15.7$ & $37.6 \pm 13.3$ & 0.02 \\
Adipose tissue (\%) & $12.0 \pm 4.4$ & $12.5 \pm 4.2$ & 0.60 \\
Calcified tissue (\%) & $2.5 \pm 3.1$ & $3.4 \pm 2.9$ & 0.21 \\
\hline
\end{tabular}

arterial uptake and arterial calcification burden. Those authors demonstrated that $41 \%$ of patients with severely calcified atheroma (calcium scores $>1000$ ) rarely demonstrated a positive ${ }^{18} \mathrm{~F}-\mathrm{NaF}$ uptake, but there was strong tracer accumulation at the peri-region of severe calcification [11]. They also suggested that ${ }^{18} \mathrm{~F}-\mathrm{NaF}$ might indicate active calcification.

As a consequence, arterial ${ }^{18} \mathrm{~F}-\mathrm{NaF}$ uptake might act as a biomarker of on-site metabolic osteogenesis related to the specific surface density of hydroxyapatite, rather than simply the intraplaque calcification burden. And, regionally increased ${ }^{18} \mathrm{~F}-\mathrm{NaF}$ uptake might indicate active calcium growth occurring at the border region of severe calcification. Furthermore, this could be due to the heterogeneity of plaques and the dynamic interplay between macrophage-derived microcalcification [25] and smooth muscle cell-derived macrocalcification [26].

In this study, we observed ${ }^{18} \mathrm{~F}-\mathrm{NaF}$ uptake at fibrocalcific lesions, indicating an association between the vascular ${ }^{18} \mathrm{~F}$ $\mathrm{NaF}$ uptake and the mineralization of plaques. Moreover, ${ }^{18} \mathrm{~F}-\mathrm{NaF}$ uptake was absent in several calcified coronary lesions. There are several reasons which may contribute to this. (1) There was increased partial volume effect on PET scans for small lesions. (2) The ${ }^{18} \mathrm{~F}-\mathrm{NaF}$ interplay with the calcium salt of hydroxyapatite depends on the nature of the specimen, and real localized osteogenic bioactivity is still unclear. Additionally, although hydroxyapatite is a critical component in the progression of vascular intimal calcification [21], various types of calcium salts deposit within an atherosclerotic artery [27]. (3) There is increased incorporation of ${ }^{18} \mathrm{~F}-\mathrm{NaF}$ with the newly formed hydroxyapatite compared to old hydroxyapatite crystals [28]; thus, the adsorption of fluoride to hydroxyapatite is discrepant between patients and lesions. (4) Activation of covalent binding between sodium fluoride and arterial hydroxyapatite components under various physiological or chemical conditions might be another alternative. 
Fig. 5 Graphs show correlation of coronary ${ }^{18} \mathrm{~F}-\mathrm{NaF}$ mTRB ${ }_{\text {max }}$ versus clinical serum profiles. Cardiovascular biomarkers, including HDL, LDL, cholesterol level, and hsCRP level were assessed. mTBRmax: mean of $\mathrm{TBR}_{\max }$ from all ROIs placed in individual patient. $* \mathrm{p}$ value $<0.05$
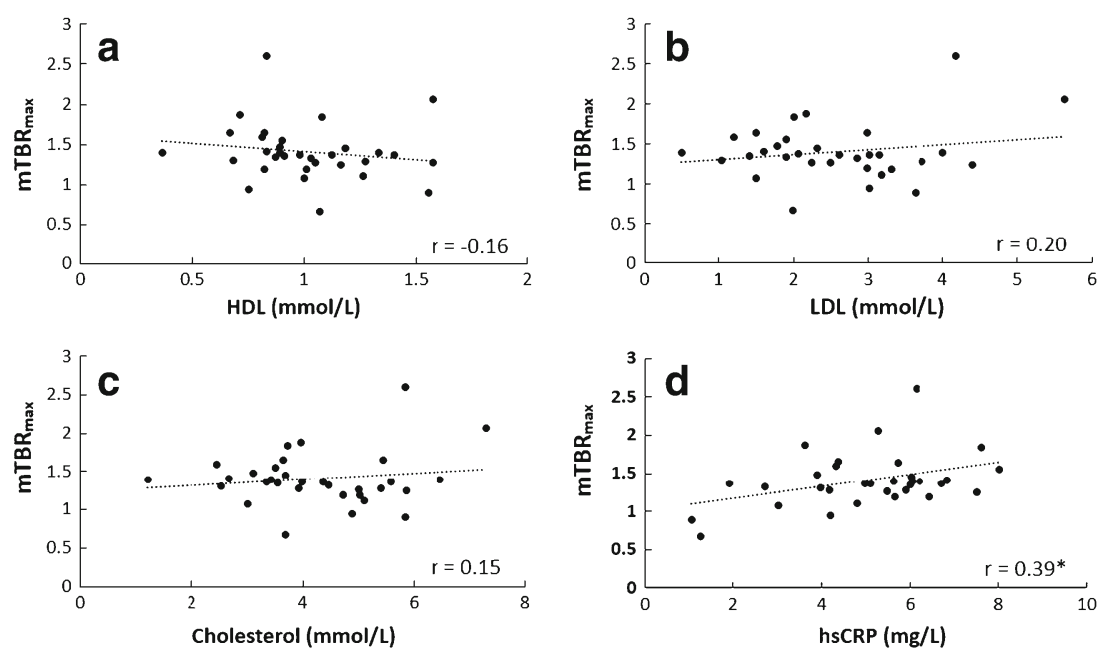

Indeed, we proposed that the anatomical composition on $\mathrm{CT}$ with respect to increased real-time ${ }^{18} \mathrm{~F}-\mathrm{NaF}$ uptake at plaque lesions reflected underlying hypometabolism; however, the pattern of temporal evolution of osteogenesis and inflammation during plaque growth was not confirmed in prior studies, where in particular the tracer kinetics of ${ }^{18} \mathrm{~F}-\mathrm{NaF}$ in arterial lesions are still unclear. Therefore, to detect the vasculature formation of hydroxyapatite over time is a major task for ${ }^{18} \mathrm{~F}-\mathrm{NaF}$ coronary PET.

Using IVUS as an anatomical reference, we found the ${ }^{18} \mathrm{~F}-\mathrm{NaF}$ uptake was not directly associated with arterial calcium burden, but more intensively accumulated in the atheroma with spotty calcification and calcified fibroatheroma.

In our study, ${ }^{18} \mathrm{~F}-\mathrm{NaF}$ uptake significantly correlated with serum hsCRP level which is a reliable surrogate biomarker for systemic inflammation in diagnosis of cardiovascular diseases [29]. Furthermore, there was a trend towards higher ${ }^{18} \mathrm{~F}-\mathrm{NaF}$ uptake along with increased LDL and cholesterol levels, which indicates the association between systemical risk markers and the presence of arterial inflammation in the coronaries.

\section{Limitation}

Coronary arterial PET is challenging because of small plaque sizes and cardiac motion. The artifacts related to increased partial volume effects and cardiac motion should not be ignored. Also, due to different image formats of the applied methods, 3D fusion was not possible. Given these limitations, misalignment between PET and $\mathrm{CT}$ as well as PET/CT and IVUS cannot be excluded. We also acknowledge the small patient population recruited in this study; we were also lacking histological evidence of coronary plaques to correlate with in vivo imaging as well as motion compensation and partial volume correction for
${ }^{18} \mathrm{~F}-\mathrm{NaF}$ PET/CT imaging of coronary plaque. There were no early atherosclerotic lesions or healthy lesions selected in the IVUS setting, and no invasive morphological evidence was provided to correlate with negative ${ }^{18} \mathrm{~F}-\mathrm{NaF}$ findings. We also could not exclude pharmaceutical effects on the imaging data.

\section{Conclusion}

For the global evaluation of atherosclerotic plaques, the combination of ${ }^{18} \mathrm{~F}-\mathrm{NaF}$ PET and anatomical CT might be employed to provide morphological information about plaque burden, as well as pathophysiological osteogenesis. In clinical practice, ${ }^{18} \mathrm{~F}-\mathrm{NaF}$ PET/CT showed great potential as an adjunctive noninvasive imaging tool to coronary catheterization imaging for risk stratification and guiding therapy.

Acknowledgements Our study was funded by special funds of Shanxi Molecular Imaging Precision Medicine Collaborative Innovation Center $\&$ the National Natural Science Foundation of China (Grant NO. 81671724).

Funding Information Open access funding provided by Medical University of Vienna.

\section{Compliance with ethical standards}

\section{Conflict of interest None.}

Ethical approval The clinical institutional review board approved this study.

Open Access This article is distributed under the terms of the Creative Commons Attribution 4.0 International License (http:// creativecommons.org/licenses/by/4.0/), which permits unrestricted use, distribution, and reproduction in any medium, provided you give appropriate credit to the original author(s) and the source, provide a link to the Creative Commons license, and indicate if changes were made. 


\section{References}

1. Bentzon JF, Otsuka F, Virmani R, Falk E. Mechanisms of plaque formation and rupture. Circ Res. 2014;114:1852-66. https://doi. org/10.1161/CIRCRESAHA.114.302721.

2. Tousoulis D, Davies G, Stefanadis C, Toutouzas P, Ambrose JA. Inflammatory and thrombotic mechanisms in coronary atherosclerosis. Heart. 2003;89:993-7.

3. Greenland P, Gaziano JM. Clinical practice. Selecting asymptomatic patients for coronary computed tomography or electrocardiographic exercise testing. N Engl J Med. 2003;349:465-73. https:// doi.org/10.1056/NEJMcp023197.

4. Vengrenyuk Y, Carlier S, Xanthos S, Cardoso L, Ganatos P, Virmani R, et al. A hypothesis for vulnerable plaque rupture due to stress-induced debonding around cellular microcalcifications in thin fibrous caps. Proc Natl Acad Sci USA. 2006;103:14678-83. https://doi.org/10.1073/pnas.0606310103.

5. Sinclair H, Bourantas C, Bagnall A, Mintz GS, Kunadian V. OCT for the identification of vulnerable plaque in acute coronary syndrome. JACC Cardiovasc Imaging. 2015;8:198-209. https://doi. org/10.1016/j.jcmg.2014.12.005.

6. Kataoka Y, Wolski K, Uno K, Puri R, Tuzcu EM, Nissen SE, et al. Spotty calcification as a marker of accelerated progression of coronary atherosclerosis: insights from serial intravascular ultrasound. J Am Coll Cardiol. 2012;59:1592-7. https://doi.org/10.1016/j.jacc.2012.03.012.

7. Motoyama S, Ito H, Sarai M, Kondo T, Kawai H, Nagahara Y, et al. Plaque characterization by coronary computed tomography angiography and the likelihood of acute coronary events in mid-term follow-up. J Am Coll Cardiol. 2015;66:337-46. https://doi.org/10. 1016/j.jacc.2015.05.069.

8. Cai JM, Hatsukami TS, Ferguson MS, Small R, Polissar NL, Yuan C. Classification of human carotid atherosclerotic lesions with in vivo multicontrast magnetic resonance imaging. Circulation. 2002;106:1368-73.

9. Hecht HS, Cronin P, Blaha MJ, Budoff MJ, Kazerooni EA, Narula $\mathrm{J}$, et al. 2016 SCCT/STR guidelines for coronary artery calcium scoring of noncontrast noncardiac chest CT scans: a report of the Society of Cardiovascular Computed Tomography and Society of thoracic radiology. J Cardiovasc Comput Tomogr. 2017;11:74-84. https://doi.org/10.1016/j.jcct.2016.11.003.

10. Schartl M, Bocksch W, Koschyk DH, Voelker W, Karsch KR, Kreuzer J, et al. Use of intravascular ultrasound to compare effects of different strategies of lipid-lowering therapy on plaque volume and composition in patients with coronary artery disease. Circulation. 2001;104:387-92.

11. Dweck MR, Chow MW, Joshi NV, Williams MC, Jones C, Fletcher AM, et al. Coronary arterial 18F-sodium fluoride uptake: a novel marker of plaque biology. J Am Coll Cardiol. 2012;59:1539-48. https://doi.org/10.1016/j.jacc.2011.12.037.

12. Joshi NV, Vesey AT, Williams MC, Shah AS, Calvert PA, Craighead $\mathrm{FH}$, et al. 18F-fluoride positron emission tomography for identification of ruptured and high-risk coronary atherosclerotic plaques: a prospective clinical trial. Lancet. 2014;383:705-13. https://doi.org/10.1016/S0140-6736(13)61754-7.

13. Levine GN, Bates ER, Blankenship JC, Bailey SR, Bittl JA, Cercek $\mathrm{B}$, et al. $2011 \mathrm{ACCF} / \mathrm{AHA} / \mathrm{SCAI}$ guideline for percutaneous coronary intervention. A report of the American College of Cardiology Foundation/American Heart Association task force on practice guidelines and the Society for Cardiovascular Angiography and Interventions. J Am Coll Cardiol. 2011;58:e44-122. https://doi. org/10.1016/j.jacc.2011.08.007.

14. Levine GN, Bates ER, Blankenship JC, Bailey SR, Bittl JA, Cercek B, et al. 2015 ACC/AHA/SCAI focused update on primary percutaneous coronary intervention for patients with ST-elevation myocardial infarction: an update of the 2011 ACCF/AHA/SCAI guideline for percutaneous coronary intervention and the 2013 ACCF/AHA guideline for the management of ST-elevation myocardial infarction. J Am Coll Cardiol. 2016;67:1235-50. https://doi. org/10.1016/j.jacc.2015.10.005.

15. Otsuka F, Joner M, Prati F, Virmani R, Narula J. Clinical classification of plaque morphology in coronary disease. Nat Rev Cardiol. 2014;11:379-89. https://doi.org/10.1038/nrcardio.2014.62.

16. Stone GW, Maehara A, Lansky AJ, de Bruyne B, Cristea E, Mintz GS, et al. A prospective natural-history study of coronary atherosclerosis. N Engl J Med. 2011;364:226-35. https://doi.org/10.1056/ NEJMoa1002358.

17. Li X, Heber D, Cal-Gonzalez J, Karanikas G, Mayerhoefer ME, Rasul S, et al. Association between osteogenesis and inflammation during the progression of calcified plaque evaluated by (18)F-fluoride and (18)F-FDG. J Nucl Med. 2017;58:968-74. https://doi.org/ 10.2967/jnumed.116.182790.

18. Li X, Heber D, Leike T, Beitzke D, Lu X, Zhang X, et al. [68Ga]Pentixafor-PET/MRI for the detection of Chemokine receptor 4 expression in atherosclerotic plaques. Eur J Nucl Med Mol Imaging. 2017. https://doi.org/10.1007/s00259-017-3831-0.

19. Tardif JC, Lesage F, Harel F, Romeo P, Pressacco J. Imaging biomarkers in atherosclerosis trials. Circ Cardiovasc Imaging. 2011;4: 319-33. https://doi.org/10.1161/CIRCIMAGING.110.962001.

20. Detrano R, Guerci AD, Carr JJ, Bild DE, Burke G, Folsom AR, et al. Coronary calcium as a predictor of coronary events in four racial or ethnic groups. N Engl J Med. 2008;358:1336-45. https://doi.org/ 10.1056/NEJMoa072100.

21. Dmitrovsky E, Boskey AL. Calcium-acidic phospholipid-phosphate complexes in human atherosclerotic aortas. Calcif Tissue Int. 1985;37:121-5.

22. Zaheer A, Murshed M, De Grand AM, Morgan TG, Karsenty G, Frangioni JV. Optical imaging of hydroxyapatite in the calcified vasculature of transgenic animals. Arterioscler Thromb Vasc Biol. 2006;26:1132-6. https://doi.org/10.1161/01.ATV.0000210016. 89991.2a.

23. McCollough CH, Ulzheimer S, Halliburton SS, Shanneik K, White RD, Kalender WA. Coronary artery calcium: a multi-institutional, multimanufacturer international standard for quantification at cardiac CT. Radiology. 2007;243:527-38. https://doi.org/10.1148/ radiol.2432050808.

24. Irkle A, Vesey AT, Lewis DY, Skepper JN, Bird JL, Dweck MR, et al. Identifying active vascular microcalcification by (18)F-sodium fluoride positron emission tomography. Nat Commun. 2015;6: 7495. https://doi.org/10.1038/ncomms8495.

25. New SE, Goettsch C, Aikawa M, Marchini JF, Shibasaki M, Yabusaki K, et al. Macrophage-derived matrix vesicles: an alternative novel mechanism for microcalcification in atherosclerotic plaques. Circ Res. 2013;113:72-7. https://doi.org/10.1161/ CIRCRESAHA.113.301036.

26. Kapustin AN, Shanahan CM. Calcium regulation of vascular smooth muscle cell-derived matrix vesicles. Trends Cardiovasc Med. 2012;22:133-7. https://doi.org/10.1016/j.tcm.2012.07.009.

27. Schmid K, McSharry WO, Pameijer CH, Binette JP. Chemical and physicochemical studies on the mineral deposits of the human atherosclerotic aorta. Atherosclerosis. 1980;37:199-210.

28. Segall G, Delbeke D, Stabin MG, Even-Sapir E, Fair J, Sajdak R, et al. SNM practice guideline for sodium $18 \mathrm{~F}$-fluoride $\mathrm{PET} / \mathrm{CT}$ bone scans 1.0. J Nucl Med. 2010;51:1813-20. https://doi.org/10.2967/ jnumed.110.082263.

29. Ridker PM, Hennekens CH, Buring JE, Rifai N. C-reactive protein and other markers of inflammation in the prediction of cardiovascular disease in women. N Engl J Med. 2000;342:836-43. https:// doi.org/10.1056/NEJM200003233421202. 